\title{
Article \\ Effect of Assembly Errors on Ground Tooth Surface Deviations for Large-Scale CNC Gear Profile Grinding Machines
}

\author{
Wenzheng Ding ${ }^{1, *}$, Wenquan $\mathrm{He}^{1}{ }^{1}$ Hu Zhang ${ }^{2}$ and Yao $\mathrm{Li}^{1}$ \\ 1 Jiangsu Key Laboratory of Advanced Numerical Control Technology, Nanjing Institute of Technology, \\ Nanjing 211167, China; 15195859067@163.com (W.H.); liyaokkx@njit.edu.cn (Y.L.) \\ 2 Nanjing Gongda CNC Technology Co., Ltd., Nanjing 211816, China; hellozhanghu@163.com \\ * Correspondence: njgdsk133@126.com
}

check for updates

Citation: Ding, W.; He, W.; Zhang, H.; Li, Y. Effect of Assembly Errors on Ground Tooth Surface Deviations for Large-Scale CNC Gear Profile Grinding Machines. Machines 2022, 10, 111. https://doi.org/10.3390/ machines10020111

Academic Editor: Kai Cheng

Received: 30 December 2021

Accepted: 28 January 2022

Published: 1 February 2022

Publisher's Note: MDPI stays neutral with regard to jurisdictional claims in published maps and institutional affiliations.

Copyright: (C) 2022 by the authors. Licensee MDPI, Basel, Switzerland. This article is an open access article distributed under the terms and conditions of the Creative Commons Attribution (CC BY) license (https:// creativecommons.org/licenses/by/ $4.0 /)$.

\begin{abstract}
Assembling plays a significant role in the performance of large-scale CNC gear profile grinding machines. An approach in the deviation evaluation of ground tooth surfaces taking into account assembly errors is proposed in this paper. Based on the error transmission chain of the profile grinding system and the conjugate motion relationship between the grinding wheel and the workpiece, the ground tooth surface model including assembly errors was established using the surface envelope method. Then, the effect of assembly errors on deviations of the profile grinding tooth surface was quantitatively analyzed. The optimized distribution of assembly errors and machining verifications were performed on large-scale $\mathrm{CNC}$ gear profile grinding machines. The results show that the proposed method is effective at ensuring ground tooth surface deviations for large-scale $\mathrm{CNC}$ gear profile grinding machines.
\end{abstract}

Keywords: assembly error; deviation of tooth surface; gear profile grinding machine; spiral deviation; tooth profile deviation

\section{Introduction}

Large module precision gears with hardened tooth surfaces are widely used in the fields of wind power, ships, engineering machinery, etc. The tooth surface accuracy directly affects the performance and lifetime of the equipment seriously, such as transmission accuracy, transmission efficiency, and transmission noise. Grinding is suitable for manufacturing in hard materials because of the abrasive grains' hardness and their stout cutting wedges with negative rake angles [1]. Laser technology imposes pressure in grinding for hard materials' manufacturing. However, it has higher costs [2]. In many industrial applications, grinding processes are often the final step in the process towards finished workpieces, which means that no subsequent postgrinding correction of the surface and geometry is performed [3]. Therefore, grinding is the most important finishing process in manufacturing large module precision gears with hardened tooth surfaces.

From 1961 to the present day, researchers have made advances in many areas of grinding technology, such as process principles, machine design, tool design, process optimization, and control technology. Nevertheless, grinding today still requires test pieces to begin a long process run, which clearly indicates the necessity of grinding research and development in grinding machines [4]. Grinding machines can be classified into beltgrinding machines, stroke grinding machines, and grinding machines with rotating tools. A further level of classification for grinding machines with rotating tools distinguishes between cylindrical, planar, tool, and gear grinding machines [5].

There are two primary productive methods for gear grinding machines: the profile grinding method and the generating grinding method [6]. The profile grinding method, a single-indexing process, was developed by Niles, Gleason-Pfauter, and Luren Precision; the generating grinding method, a continuous-indexing process was developed by Reishauer and Gleason [7]. These two methods use different tools: a form wheel and a worm wheel. 
The rotation angles of the wheel and the workpiece are independent in the former but have a timed relationship in the latter. To meet the demands of the large module gears used, profile correction is especially needed for application on tooth surfaces to increase the gear load capability and to reduce noise [8]. One major concern in gear grinding machine is how to flexibly produce the gears with profile correction. The profile grinding method is more powerful than the generating grinding method for manufacturing large module gears with profile correction, especially when the CNC gear profile grinding machine is developed, because it has enough degrees of freedom to modify the tooth surfaces. Furthermore, the profile grinding method can achieve a high grinding efficiency due to line contact between the grinding wheel and the gear in this process [9]. A CNC gear profile grinding machine not only offers a simultaneous five-axis movement that enables free-form grinding but also includes an NC dressing device for wheel profile modification, so it is suitable for finishing large module gears.

The ground tooth surface deviations are the major target parameter for a gear profile grinding machine, and they are mainly caused by grinding interference and machine errors (including assembly errors, geometric errors, and thermal errors) [4]. The former can be reduced by adjusting setting the parameters and radius of the wheel. However, the latter is more complex. Compared with geometric errors and thermal errors, the assembly errors vary little over time. It is an effective way to control the ground tooth surface deviations by optimizing the assembly errors. Therefore, it is very beneficial to understand the mapping relationship between assembly errors and ground tooth surface deviations, but there is little literature published about it.

In the related literature, the geometric errors were first investigated and a model of a CNC gear profile grinding machine was then established to predict and compensate for geometric errors $[10,11]$. Subsequently, thermal error compensation was used to improve the gear grinding accuracy. A theoretical model of thermal errors for transmission chain in the large CNC gear profile grinding machine was proposed to guide the error compensation [12]. The influence of thermal errors on pitch errors was investigated successively, and a cross-tooth index machining method was proposed to reduce the pitch errors [13]. In extensive research, Zhang et al. presented a motion control method to improve the gear grinding accuracy. The minimum difference between the actual topological deviations of the tooth surface and the target topological deviations was taken as the optimization objective, and then, the tooth surface distortion resulting from tooth orientation modification was effectively eliminated by optimizing the five-axis motion control of the gear grinding machine [14]. An evaluation approach for tooth orientation modification errors of profile grinding gears was developed, and an optimization method adjusting the installation parameters of grinding wheel and workpiece was proposed, which effectively reduced the tooth direction modification errors of helical gears [15]. More recently, the reasonable selection of grinding wheel installation angles and grinding wheel radius was proposed as another feasible method. Ding et al. judged the grinding interference by computing the induced normal curvature, which is any point of the contact line between the grinding wheel surface and the gear surface, and then the setting parameters of grinding wheel were obtained under the condition of grinding without interference [16]. The contact line of the profile grinding wheel investigated by Li et al. and the optimal installation angle of the grinding wheel were accurately calculated. The machining efficiency was improved, and the grinding interference was avoided at this optimal installation angle [17]. Ding et al. investigated the assembly errors of a five-axis machine tool based on the homogeneous coordinate transformation method, and the assembly errors were compensated in NC codes through reverse decoupling [18]. The influence of assembly errors on the motion accuracy was analyzed for feed systems of CNC machine tools [19]. Lee et al. investigated the effect of assembly errors on volumetric errors for a five-axis machine tool, and they recognized the error terms that cannot be compensated by driving single control axis [20]. Nevertheless, tooth surface deviations in profile grinding were not referred to in the above work. Xia et al. proposed a model of tooth surface deviations and geometric errors for a 
five-axis gear profile grinding machine, and critical errors and sensitive components were identified by sensitivity analysis method [21]; however, assembly errors were not referred to in that research.

Assembly errors should especially be considered in large-scale CNC gear profile grinding machines for finish machining. On one hand, assembly errors are affected by the dimensional tolerances of assembly parts. Smaller assembly errors are bound to require higher accuracy of assembly parts. An excessively high accuracy is difficult to manufacture, and the machining cost will increase sharply $[4,22,23]$. On the other hand, assembly operations of large machines are more difficult with respect to conventional size machines and need to be addressed. Looser assembly errors are beneficial for the assembling of large-scale CNC gear profile grinding machines [24-27]. The objective of this paper is to analyze and optimally distribute assembly errors of large-scale CNC gear profile grinding machines in terms of ground tooth surface deviations.

The structure of the rest of this paper is as follows. Tooth surface modeling including assembly errors is described in detail in Section 2. Section 3 proposes an approach to evaluate tooth surface deviations in gear profile grinding. Calculation analysis and experiment are presented in Section 4. Finally, Section 5 provides the conclusions.

\section{Tooth Surface Modeling including Assembly Errors}

\subsection{Assembly Errors of Grinding System}

As shown in Figure 1, the large CNC gear profile grinding machine has four translations axes and two rotation axes. The $X$ axis is along the column movement direction. The $\mathrm{Y}$ axis is parallel to the grinding wheel rotation axis. The $\mathrm{Z}$ axis is parallel to the workpiece rotation axis. The $\mathrm{W}$ axis is parallel to the radial direction of the grinding wheel. The grinding spindle swing is the A axis, and the workpiece rotation is the C axis. In addition, there are three spindles: grinding spindle SP1, and dressing spindles SP2 and SP3. The gear grinding system includes the $X$ axis, the $Y$ axis, the $Z$ axis, the $A$ axis, the $C$ axis, and SP1. The grinding wheel dressing system includes the $Y$ axis, the $W$ axis, SP2, and SP3. Before grinding can take place, the grinding wheel must be dressed by the diamond roller with the simultaneous movement of the grinding wheel dressing system. The kinematic chain of the gear grinding system (shown in Figure 2) is more complex than that of the grinding wheel dressing system. Therefore, assembly errors of the gear grinding system are highlighted in this paper.
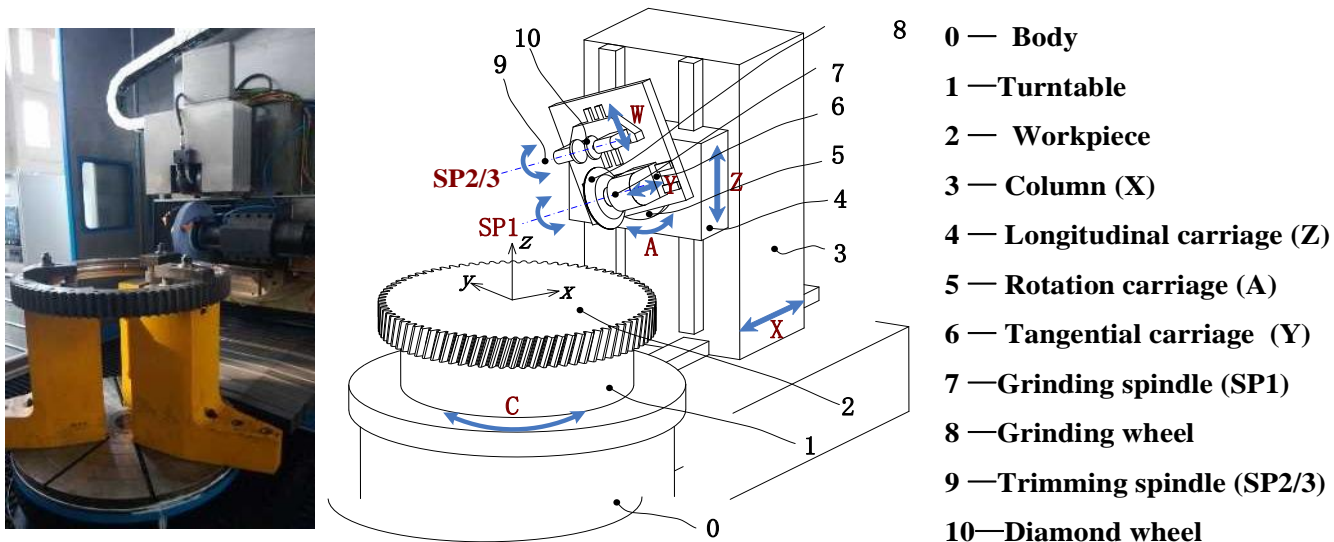

Figure 1. Schematic of a large-scale CNC gear profile grinding machine. 


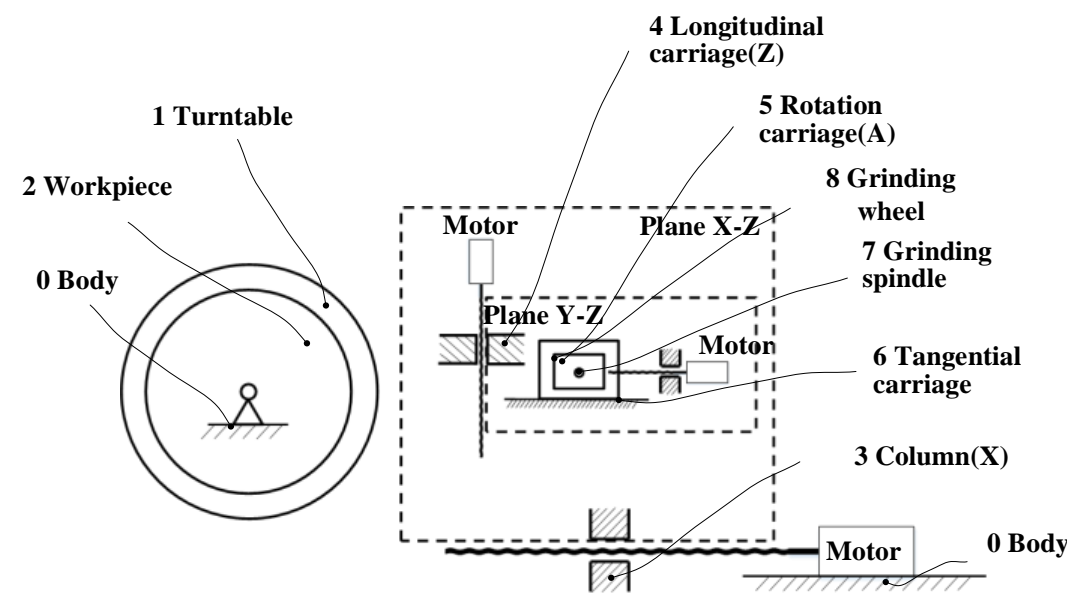

Figure 2. Kinematic chain of the gear grinding system.

To investigate the effect of assembly errors on ground tooth surface deviations, the coordinate system transformation with assembly errors was established to describe the spatial relationship between critical components. In Figure 3, S represents the coordinate system. The number in the subscript of $S$ represents the corresponding component in Figure 2, and the small $\mathrm{s}$ and $\mathrm{d}$ attached to the number represent the stationary coordinate system and the moving coordinate system of the same component, respectively. $\mathrm{S}_{\mathrm{a}}, \mathrm{S}_{\mathrm{b}}, \mathrm{S}_{\mathrm{c}}$, and $S_{d}$ are auxiliary coordinate systems. The assembly errors of the gear grinding system are shown in Table 1.

$$
S_{0} \stackrel{\delta \beta_{0,1 \mathrm{~s}}}{\longrightarrow} S_{\mathrm{a}} \stackrel{\delta \alpha_{0,1 \mathrm{~s}}}{\longrightarrow} S_{1 \mathrm{~s}} \stackrel{\varphi_{\mathrm{c}}+\delta \varphi_{\varphi_{1}}}{\longrightarrow} S_{1 \mathrm{~d}} \longrightarrow S_{2}
$$

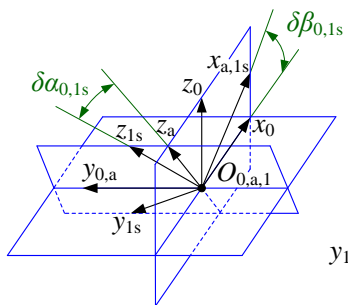

(a)

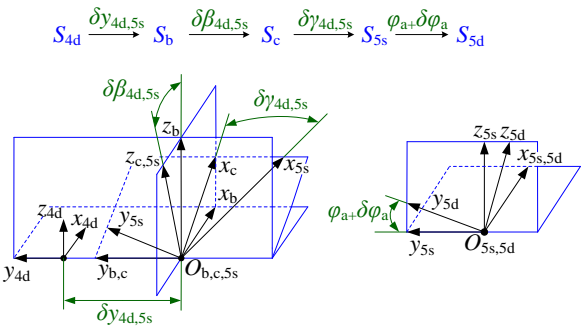

(c)

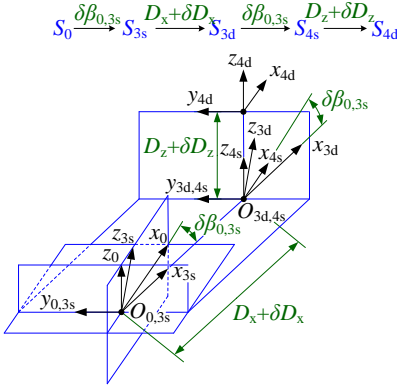

(b)

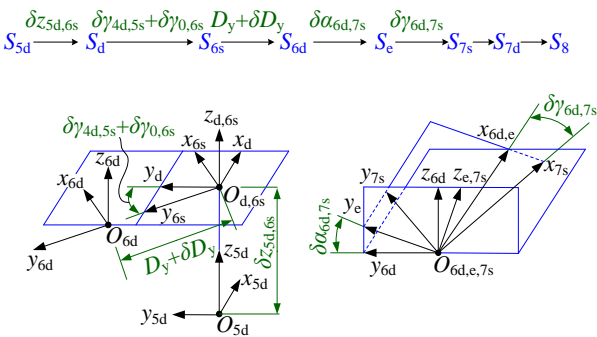

(d)

Figure 3. Assembly errors and coordinate systems of the gear grinding system: (a) coordinate system $\mathrm{S}_{0}$ to coordinate system $\mathrm{S}_{2},(\mathbf{b})$ coordinate system $\mathrm{S}_{0}$ to coordinate system $\mathrm{S}_{4 \mathrm{~d}},(\mathbf{c})$ coordinate system $\mathrm{S}_{4 \mathrm{~d}}$ to coordinate system $\mathrm{S}_{5 \mathrm{~d}}$, and (d) coordinate system $\mathrm{S}_{5 \mathrm{~d}}$ to coordinate system $\mathrm{S}_{8}$. 
Table 1. Assembly errors of the gear grinding system.

\begin{tabular}{|c|c|c|c|c|c|}
\hline Number & Symbol & Meaning & Number & Symbol & Meaning \\
\hline $\mathrm{T} 1$ & $\delta D_{\mathrm{x}}$ & Offset error of the $X$-axis reference point & T9 & $\delta \beta_{0,1 \mathrm{~s}}$ & $\begin{array}{l}\text { Parallelism error between the } \mathrm{C} \text { axis and } \\
\text { the } \mathrm{Z} \text { axis in the } \mathrm{XZ} \text { plane }\end{array}$ \\
\hline $\mathrm{T} 2$ & $\delta D_{\mathrm{y}}$ & Offset error of the Y-axis reference point & T10 & $\delta \beta_{0,3 \mathrm{~s}}$ & $\begin{array}{l}\text { Perpendicularity error between the } \mathrm{X} \text { and } \\
\qquad \mathrm{Z} \text { axes }\end{array}$ \\
\hline T3 & $\delta y_{4 d, 5 s}$ & $\begin{array}{l}\text { Angle error between the axis } A \text { and the } \\
\text { axis } C\end{array}$ & T11 & $\delta \beta_{4 \mathrm{~d}, 5 \mathrm{~s}}$ & $\begin{array}{c}\text { Perpendicularity error between the A } \\
\text { and } \mathrm{Z} \text { axes }\end{array}$ \\
\hline $\mathrm{T} 4$ & $\delta D_{\mathrm{z}}$ & Offset error of the axis reference point & T12 & $\delta \varphi_{\mathrm{c}}$ & Offset error of the $\mathrm{X}$-axis reference point \\
\hline T5 & $\delta z_{5 \mathrm{~d}, 6 \mathrm{~s}}$ & Angle error between the axis A and SP1 & T13 & $\delta \gamma_{4 \mathrm{~d}, 5 \mathrm{~s}}$ & $\begin{array}{l}\text { Parallelism error between axis A and the } \\
\text { XZ plane }\end{array}$ \\
\hline T6 & $\delta \varphi_{\mathrm{a}}$ & Offset error of the A-axis reference point & T14 & $\delta \gamma_{0,6 \mathrm{~s}}$ & $\begin{array}{l}\text { Perpendicularity error between the } \mathrm{Y} \text { and } \\
\qquad \mathrm{X} \text { axes }\end{array}$ \\
\hline $\mathrm{T} 7$ & $\delta \alpha_{0,1 \mathrm{~s}}$ & $\begin{array}{l}\text { Parallelism error between the axis } C \text { and } \\
\text { the axis } Z \text { in the plane } Y Z\end{array}$ & T15 & $\delta \gamma_{6 \mathrm{~d}, 7 \mathrm{~s}}$ & Parallelism error between the $\mathrm{Y}$ axis and \\
\hline $\mathrm{T} 8$ & $\delta \alpha_{6 \mathrm{~d}, 7 \mathrm{~s}}$ & $\begin{array}{l}\text { Parallelism error of the } \mathrm{Y} \text { axis and the } \\
\text { SP1 axis in the } \mathrm{YZ} \text { plane }\end{array}$ & & & \\
\hline
\end{tabular}

\subsection{Modeling of Gear Profile Grinding Motion}

The process of gear profile grinding can be described by a mathematical model of position and posture about the grinding wheel relative to the workpiece. This model includes the above assembly errors, which can be expressed as follows:

$$
r_{2}(u, \theta ; t)={ }_{8}^{2} T(t) r_{8}(u, \theta)
$$

where $r_{8}(u, \theta)$ is the position vector of the grinding wheel surface in the tool coordinate system $S_{8} ; u$ and $\theta$ are the two shape parameters of the surface; $r_{2}(u, \theta ; t)$ is the singleparameter surface family of the grinding wheel in $S_{2}$ during a grinding motion; and $t$ is the motion parameter of surface family. ${ }_{8}^{2} T(t)$ is the homogeneous coordinate transformation matrix from $S_{8}$ to $S_{2}$, and it can be derived as follows:

$$
\begin{gathered}
{ }_{8}^{2} T(t)={ }_{1 d}^{2} T_{1 s}^{1 d} T\left(\varphi_{c}+\delta \varphi_{c}\right)_{a}^{1 s} T\left(\delta \alpha_{0,1 s}\right)_{0}^{a} T\left(\delta \beta_{0,1 s}\right)_{3 s}^{0} T\left(\delta \beta_{0,3 s}\right)_{3 d}^{3 s} T\left(D_{x}+\delta D_{x}\right)_{4 s}^{3 d} T\left(\delta \beta_{0,3 s}\right) \\
4 s T\left(D_{z}+\delta D_{z}\right)_{b}^{4 d} T\left(\delta y_{4 d, 5 s}\right)_{c}^{b} T\left(\delta \beta_{4 d, 5 s}\right)_{5 s}^{c} T\left(\delta \gamma_{4 d, 5 s}\right)_{5 d}^{5 s} T\left(\varphi_{a}+\delta \varphi_{a}\right)_{d}^{5 d} T\left(\delta z_{5 d, 6 s}\right) \\
\quad{ }_{6 s} T\left(\delta \gamma_{4 d, 5 s}+\delta \gamma_{0,6 s}\right)_{6 d}^{6 s} T\left(D_{y}+\delta D_{y}\right)_{e}^{6 d} T\left(\delta \beta_{6 d, 7 s}\right)_{7 s}^{e} T\left(\delta \alpha_{6 d, 7 s}\right)_{7 d}^{7 s} T_{8}^{7 d} T
\end{gathered}
$$

In Equation (2), the coordinate transformation matrixes between two adjacent coordinate systems can be derived according to the relationship illustrated in Figure 3, and they are summarized in Table 2.

As shown in Figure 4, the grinding wheel surface is regarded as being swept by its axial profile $\mathrm{h}-\mathrm{h}^{\prime}$ while the coordinate system $\mathrm{S}_{\mathrm{f}}$ rotates about $\mathrm{O}_{8} \mathrm{y}_{8}$ axis. $x_{f}(u)$ and $y_{f}(u)$ are coordinates of the grinding wheel axial profile $h-h^{\prime}$ in the gding wheel axial coordinate system $S_{\mathrm{f}}$. At the beginning, $\mathrm{S}_{\mathrm{f}}$ coincides with $\mathrm{S}_{8}$. Therefore, the grinding wheel surface can be expressed as follows:

$$
r_{8}(u, \theta)={ }_{f}^{8} T(\theta) r_{f}(u)
$$

where

$$
r_{f}(u)=\left[x_{f}(u), y_{f}(u), 0,1\right]^{T},{ }_{f}^{8} T(\theta)=\left[\begin{array}{cccc}
\cos (\theta) & 0 & -\sin (\theta) & 0 \\
0 & 1 & 0 & 0 \\
\sin (\theta) & 0 & \cos (\theta) & 0 \\
0 & 0 & 0 & 1
\end{array}\right]
$$


Table 2. Coordinate transformation matrix of two adjacent coordinate systems.

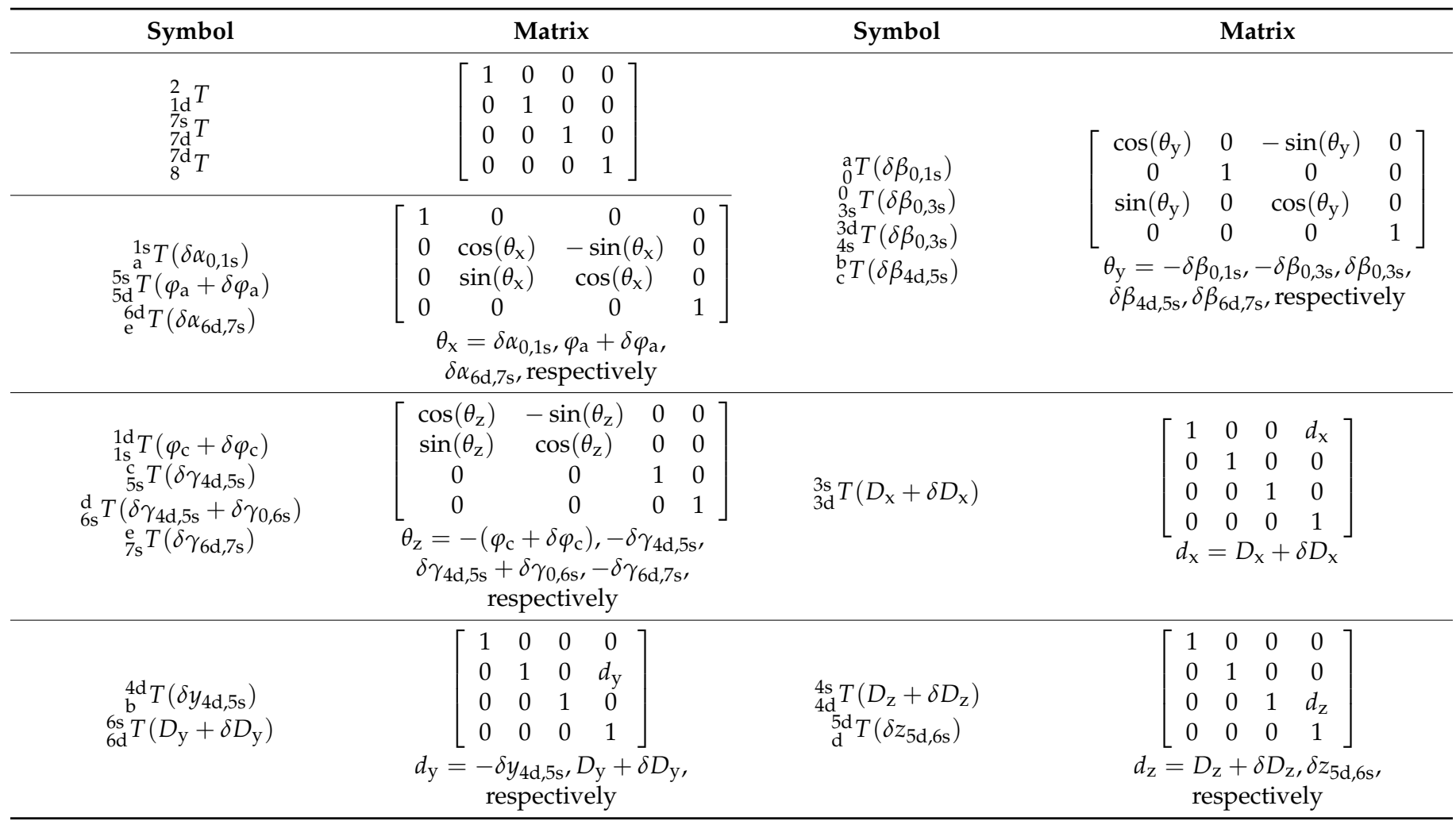
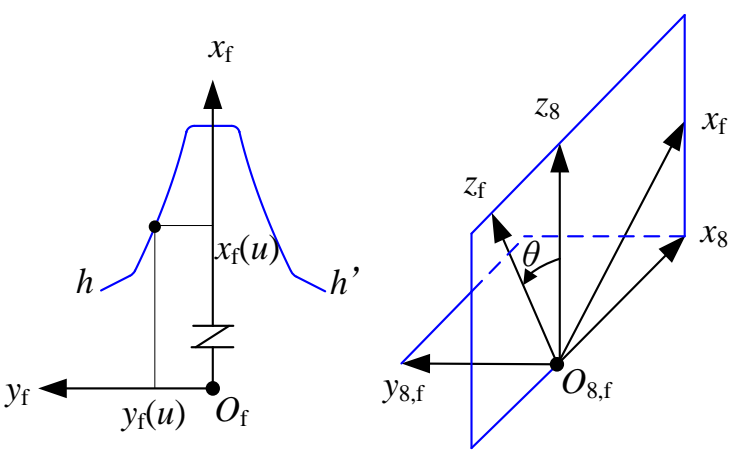

Figure 4. Wheel surface swept by its axial profile.

\subsection{Tooth Surface Modeling of Gear Profile Grinding}

To investigate the effect of assembly errors on ground tooth surface deviations, the dressing errors of the grinding wheel are ignored here. The final tooth surface of gear profile grinding is the envelope surface of a single-parameter surface family $r_{2}(u, \theta ; t)$, which can be solved as the following steps. First, the contact conditions between the surface family and the envelope surface are established. Then, the common points of tangential contact between the surface family and the envelope surface are calculated according to the above contact conditions. Finally, the envelope surface can be obtained by extracting these points. Therefore, the homogeneous transformation matrix ${ }_{8}^{2} T(t)$ in Equation (1) is rewritten into the combination of rotation transformation matrix $R(t)$ and translation vector $p(t)$; thus, Equation (1) is changed into the following:

$$
r_{2}(u, \theta ; t)={ }_{8}^{2} R(t) r_{8}(u, \theta)+{ }_{8}^{2} p(t)
$$


Then, according to the Spatial Engagement Principle, the contact conditions between the surface family and the envelope surface should meet the following conditions:

$$
\left(\frac{\partial r_{2}}{\partial u}, \frac{\partial r_{2}}{\partial \theta}, \frac{\partial r_{2}}{\partial t}\right)=0
$$

As a result, the envelope surface of the grinding wheel surface family can be obtained as follows:

$$
G(u, t)=r_{2}(u, \theta(u, t) ; t)
$$

\section{Evaluation of Tooth Surface Deviations in Gear Profile Grinding}

To evaluate the effect of assembly errors of grinding system on ground tooth surface deviations, it is necessary to evaluate the error of the solved envelope surface. In Figure 5a, there are a series of dotted grids on the theoretical tooth surface, which intersect to form many grid points. Each grid point is represented by a letter and a number. The longitudinal curve formed by a series of grid points with the same number and different letters on the same tooth surface is called the tooth trace curve. The transverse curve formed by a series of grid points with the same letter and different numbers on the same tooth surface is called the tooth profile curve. At present, gear evaluation standards (ISO:1328-1:2013, GB/T 10095.1-2008) are based on tooth profile curve and tooth trace curve, so the errors of tooth profile curve and tooth trace curve must be calculated to evaluate the ground tooth surface deviations. In Figure 5a, The mesh composed of a series of tooth profile curves and tooth trace curves is called the topological mesh. The errors between the envelope tooth surface and the theoretical tooth surface at all grid points are called the ground tooth surface deviations.

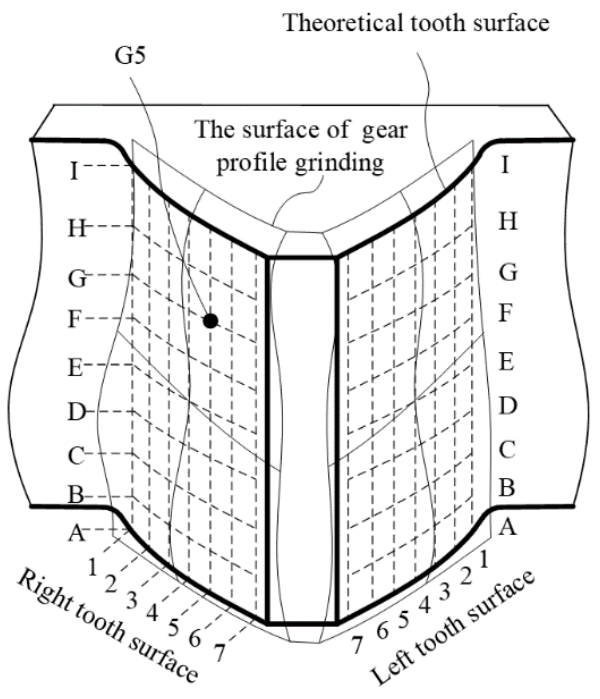

(a)
A point on the tooth surface

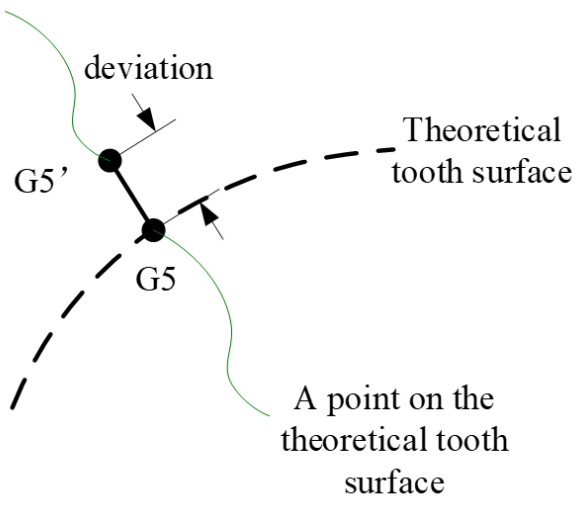

(b)

Figure 5. Deviations between the profile grinding tooth surface and the theoretical tooth surface: (a) the gear profile grinding surface and theoretical tooth surface; (b) deviation of a point on the tooth surface of gear profile grinding.

The error of each grid point is illustrated in Figure 5b. A perpendicular line was made to the theoretical tooth surface from the discrete point on the envelope surface. Then, the corresponding point on the theoretical tooth surface was obtained. The error between the above two points is the deviation of a point on the tooth surface of gear profile grinding. All of these errors were fitted and interpolated to obtain the deviations in the ground tooth surface. According to this method, tooth profile deviation, tooth profile slope deviation, helix shape deviation, helix inclination deviation, and tooth thickness deviation of gears can be calculated and the precision grade of the gear can be evaluated. The effect of the 
15 assembly errors listed in Table 1 on the ground tooth surface deviations can be analyzed based on the above method. The evaluation process is illustrated in Figure 6. There are three main steps. First, the theoretical profile $r_{f}(u)$ and coordinate transformation matrix ${ }_{8}^{2} T(t)$ are calculated. Then, the contact equation $\theta=\theta(u, t)$ is calculated, and the result is substituted into the surface family to obtain the ground envelope surface $r_{2}(u, \theta(u, t) ; t)$. Finally, the deviations in profile ground tooth surface can be evaluated.

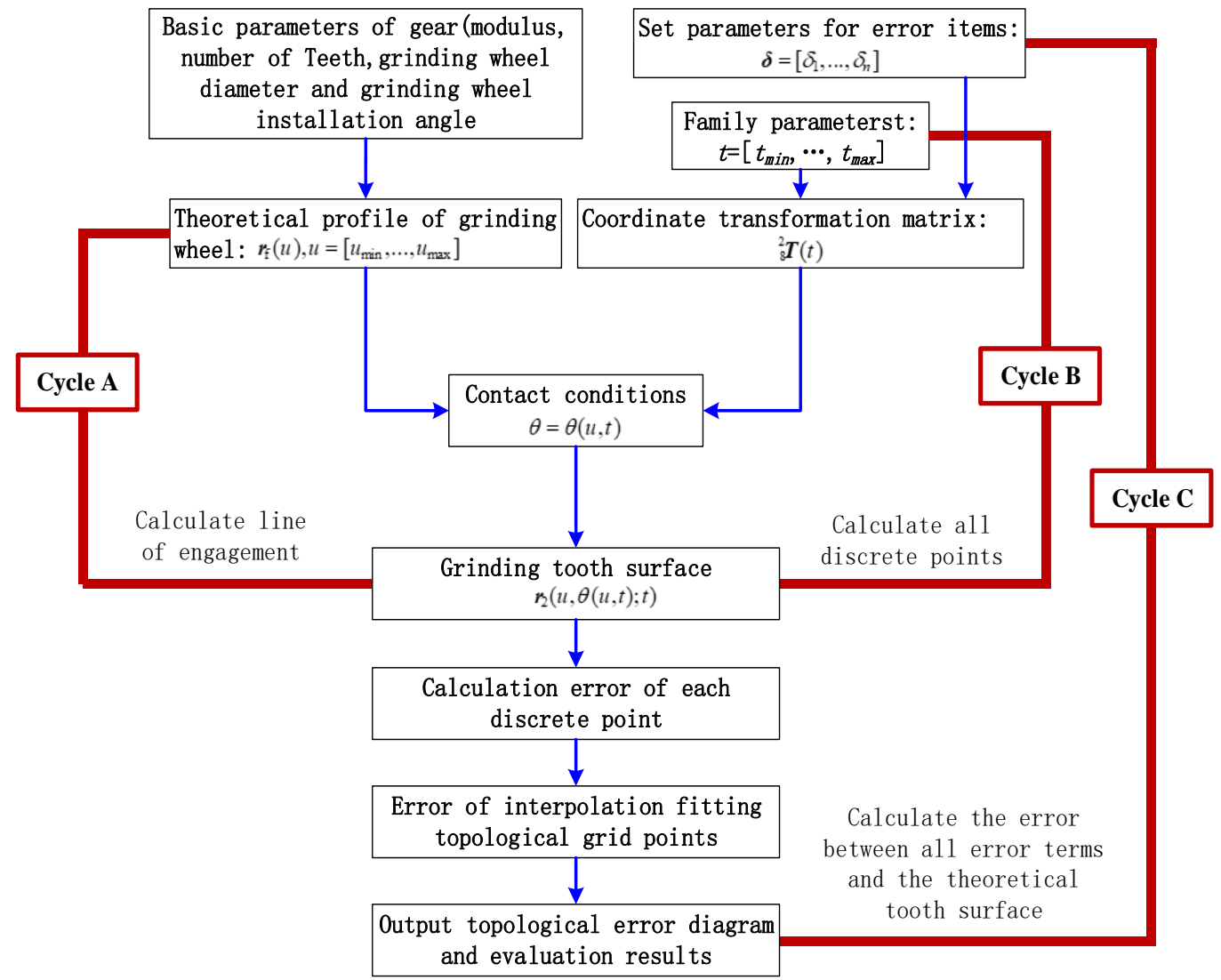

Figure 6. Evaluation flowchart of assembly errors and profile ground tooth surface deviations.

In Figure 6, three cycles-A, B, and C-were included in the evaluation flow. Cycle A is when the coordinate transformation matrix ${ }_{8}^{2} T(t)$ is determined, the contact equation is calculated for each point (different parameter $\mathrm{u}$ ) on the grinding wheel profile, and a series of contact points are obtained. Cycle B includes cycle A, and contact lines are obtained at different moments in the grinding process and are the envelope surface formed by grinding. Cycle $C$ includes cycle $C$, and its function is to set reasonable error values for different error terms, so different ground tooth surfaces are obtained and the deviation evaluation of each ground tooth surface is performed.

\section{Calculation Analysis and Error Distribution}

\subsection{Single Value Calculation and Analysis}

For a gear profile grinding, the related parameters of gear and grinding wheel are shown in Table 3. According to the flow shown in Figure 6, deviations in the ground tooth surface resulting from each error term in Table 1 are analyzed. The value of the length error term was set to $0.2 \mathrm{~mm}$, and the value of the angle error term was set to 200 arcsec. Deviations in the tooth surface corresponding to each error term are shown in Figures 7-10. $f_{H \alpha l}$ and $f_{H \alpha r}$ represent the maximum inclination deviation of the tooth profile in the left and right tooth surfaces, respectively. $f_{H \beta l}$ and $f_{H \beta r}$ represent the maximum deviation of helix inclination in the left and right tooth surfaces, respectively. $f_{S}$ represents the tooth thickness deviation corresponding to the center point of the tooth surface. In addition, the 
tooth profile shape deviation and helix shape deviation produced by 15 error terms were close to 0 .

Table 3. Related parameters of gear and grinding wheel.

\begin{tabular}{cccc|cccc}
\hline Name & Symbol & Unit & Value & Name & Symbol & Unit & Value \\
\hline Module & $m_{\mathrm{n}}$ & $\mathrm{mm}$ & 14 & Tooth breadth & $B$ & $\mathrm{~mm}$ & 200 \\
Gear number & $z$ & - & 74 & helix parameter & $p$ & $\mathrm{~mm}$ & 2001.3983 \\
Pressure angle & $\alpha_{\mathrm{n}}$ & $\mathrm{deg}$ & 20 & Grinding wheel diameter & $d_{\mathrm{w}}$ & $\mathrm{mm}$ & 380 \\
Helix angle & $\beta$ & $\mathrm{deg}$ & 15 & Grinding tooth root diameter & $d_{\mathrm{fg}}$ & $\mathrm{mm}$ & 1040 \\
Modification coefficient & $x_{\mathrm{n}}$ & - & 0 & Grinding tooth tip diameter & $d_{\mathrm{ag}}$ & $\mathrm{mm}$ & 1104 \\
Root diameter & $d_{\mathrm{f}}$ & $\mathrm{mm}$ & 1037.55 & Grinding tooth installation angle & $\gamma_{\mathrm{s}}$ & $\mathrm{deg}$ & 15 \\
Tip diameter & $d_{\mathrm{a}}$ & $\mathrm{mm}$ & 1100.55 & Grinding tooth center distance & $D_{\mathrm{x}}$ & $\mathrm{mm}$ & 710 \\
\hline
\end{tabular}

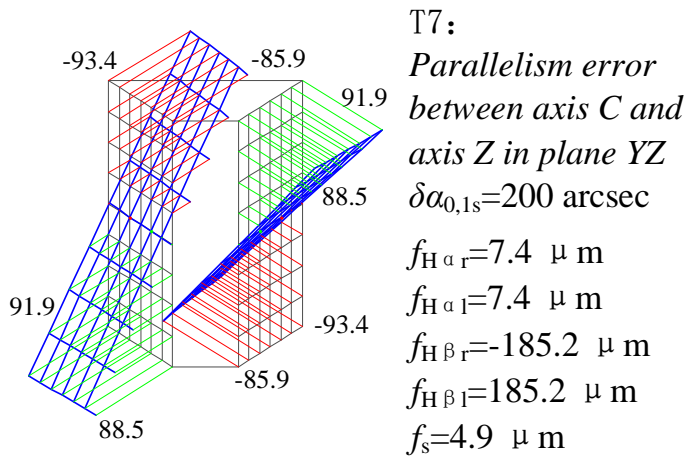

T9:

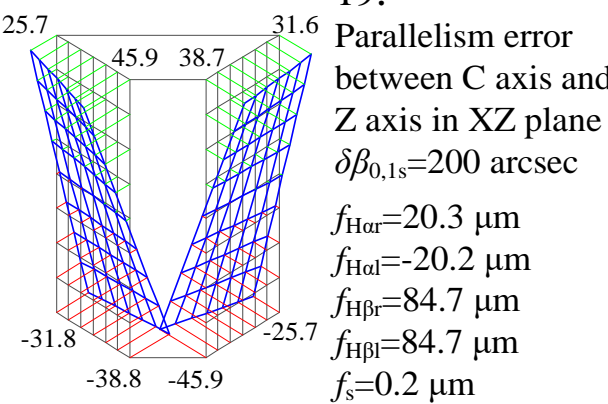

Figure 7. Deviations in tooth surface produced by assembly errors T7 and T9.
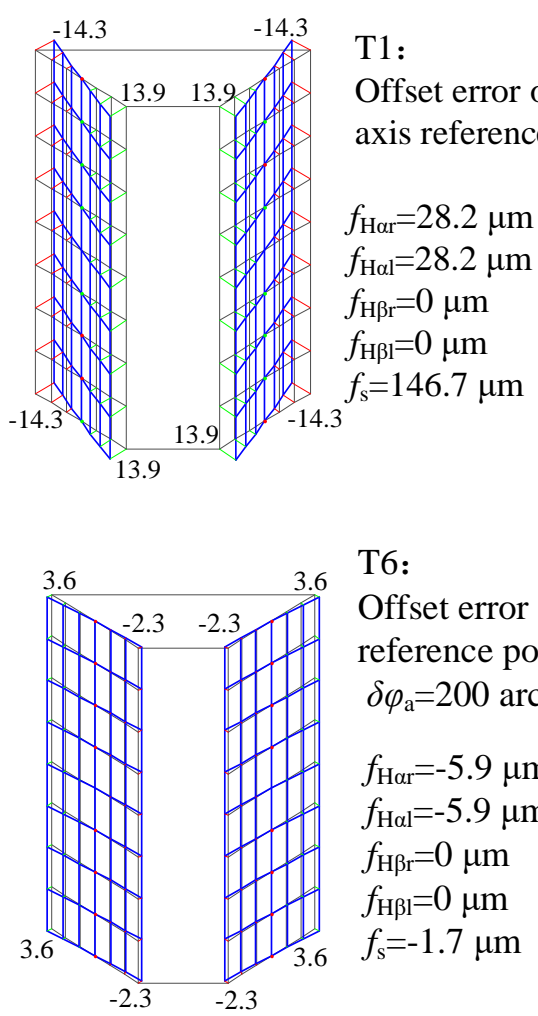

T6:

Offset error of A-axis reference point $\delta \varphi_{\mathrm{a}}=200 \operatorname{arcsec}$

$f_{\mathrm{H} \alpha \mathrm{r}}=-5.9 \mu \mathrm{m}$

$f_{\mathrm{H \alpha l}}=-5.9 \mu \mathrm{m}$

$f_{\mathrm{H \beta r}}=0 \mu \mathrm{m}$

$f_{\mathrm{H} \beta \mathrm{I}}=0 \mu \mathrm{m}$

$f_{\mathrm{s}}=-1.7 \mu \mathrm{m}$

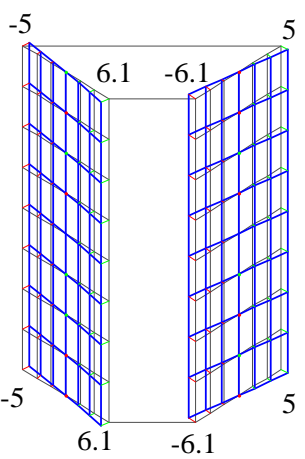

T3:

Angle error between axis $\mathrm{A}$ and axis $\mathrm{C}$

$f_{\mathrm{H \alpha r}}=-11.1 \mu \mathrm{m}$

$f_{\mathrm{H \alpha l}}=-11.1 \mu \mathrm{m}$

$f_{\mathrm{H} \beta \mathrm{r}}=0 \mu \mathrm{m}$

$f_{\mathrm{H} \beta \mathrm{I}}=0 \mu \mathrm{m}$

$f_{\mathrm{s}}=0 \mu \mathrm{m}$

Figure 8. Deviations in tooth surface produced by assembly errors T1, T3, T6, and T8.

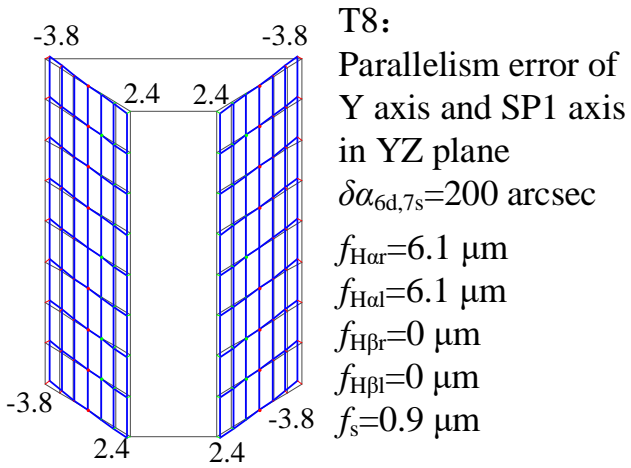




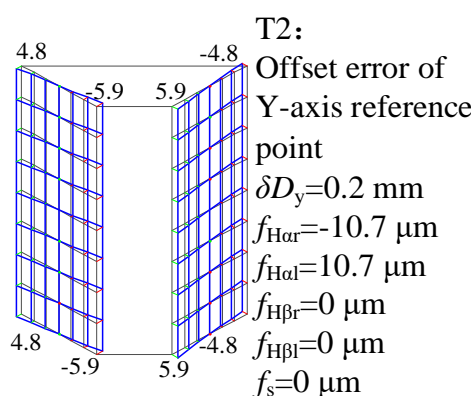

T5:
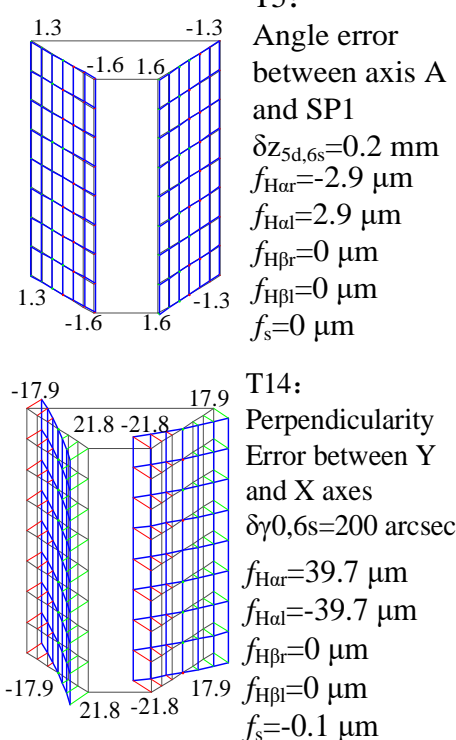

T11:
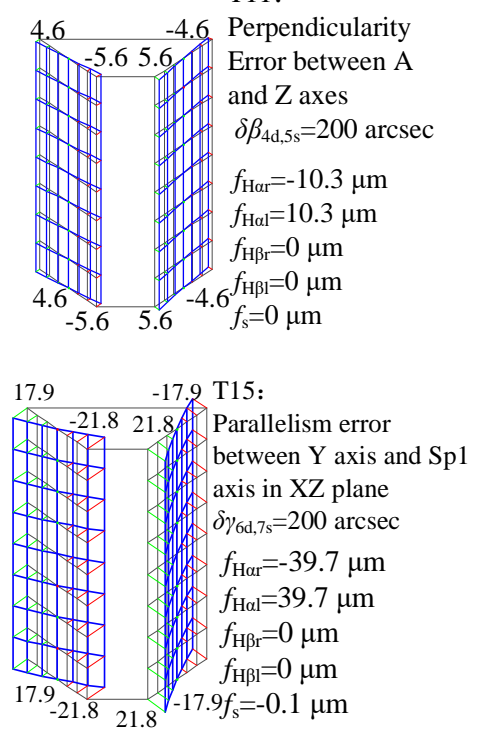

Figure 9. Deviations in tooth surface produced by assembly errors T2, T5, T11, T13, T14, and T15.
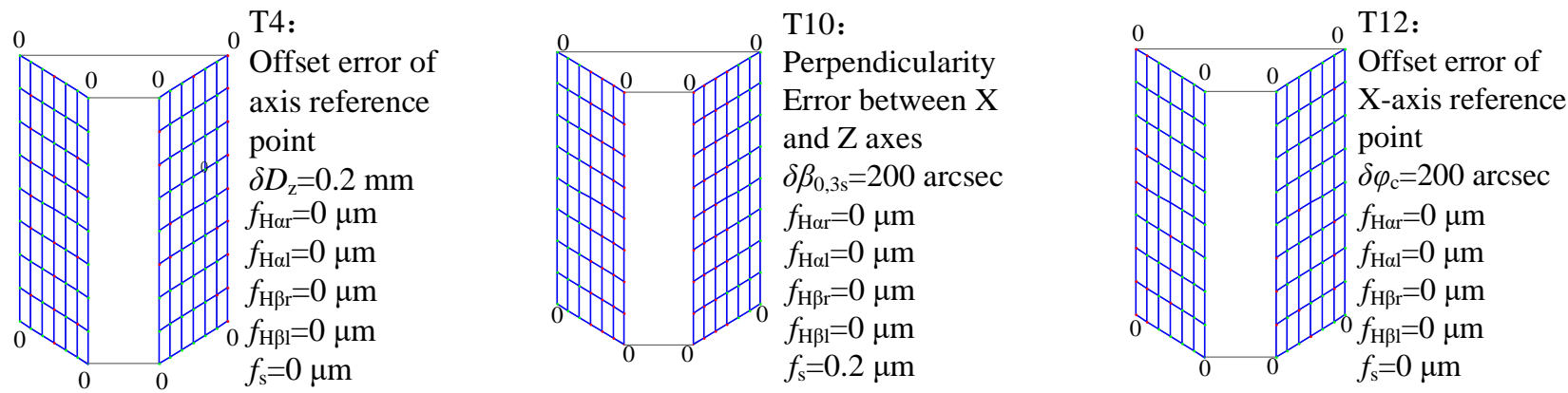

Figure 10. Deviations in tooth surface produced by assembly errors T4, T10, and T12.

More characteristics were found by further analysis. (1) The deviation value of ground tooth surfaces produced by a single error term is the same on the left and right tooth surfaces. However, some deviation directions are the same, and others are opposite. (2) Among the 15 error terms, only T7 and T9 have significant effects on the helical slop deviation. (3) T1, T2, T3, T5, T6, T8, T11, T13, T14, and T15 have effects on the profile slop deviation. As shown in Figure 8, T1, T3, T6, and T8 have the same effect on the left and right tooth surfaces, while others have opposite effects on the left and right tooth surfaces, as shown in Figure 9. (4) T6 is the offset error of the reference point of axis A, which can be regarded as the angle error of the wheel before gear grinding. When the angle error is 200 arcsec, the deviation in ground tooth surface is only about $6 \mu \mathrm{m}$. Generally, the angle error is less than 200 arcsec, so T6 has little effect on the precision of gear grinding. (5) As shown in Figure 10, T4, T10, and T12 should also to be controlled, even though they do not produce any deviations in tooth surface, because the machining allowance of the left and right tooth surfaces are affected by them. (6) T1 has a significant effect on tooth thickness deviation, while other error terms have little influence on tooth thickness deviation.

\subsection{Multi-Value Computation and Analysis}

According to the above analysis, tooth thickness deviation is affected by T1; tooth profile slop deviation is affected by T1, T2, T3, T5, T6, T8, T11, T13, T14, and T15; and helical slop deviation is affected by T7 and T9. From Figure 11, it can be seen that there is a linear relationship between $\mathrm{T} 1$ and tooth thickness deviation, and helical slop deviation also changes linearly when T7 and T9 change. From Figures 12 and 13, it can be seen that there is a linear relationship between error items of T1, T2, T3, T5, T6, T8, T11, T13, T14, and 
T15 and tooth profile slop deviation in the range of specified values. Among these error items, the tooth profile slop deviation is greatly affected by T1, T2, T3, T14, T15, and T11. The spiral slop deviation is also changed linearly with the varying of $\mathrm{T} 7$ and $\mathrm{T} 9$, as shown in Figure 14. The above analysis results show that deviations in ground tooth surface are cumulatively increased under the combined action of many assembly errors. Excessively tightening every assembly error leads to a sharp rise in accuracy of assembly parts and difficulty of assembly operations. Therefore, it is better to optimally distribute assembly errors under the limitation of deviations in ground tooth surface.

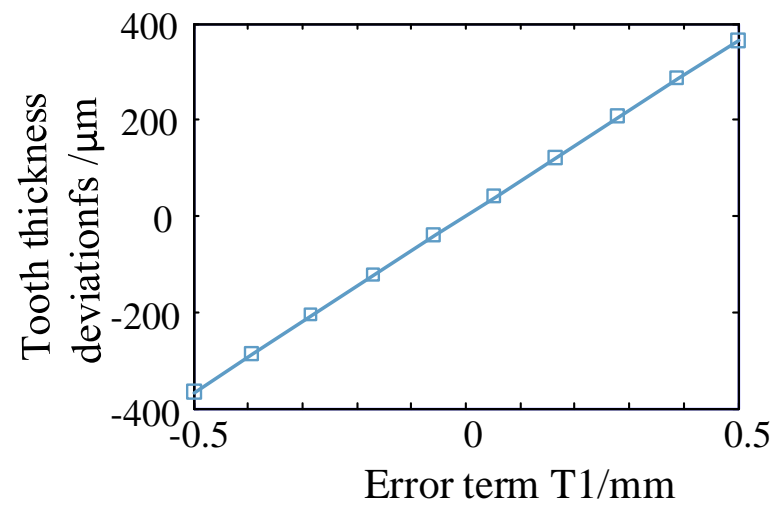

Figure 11. Relationship between tooth thickness deviation and T1.

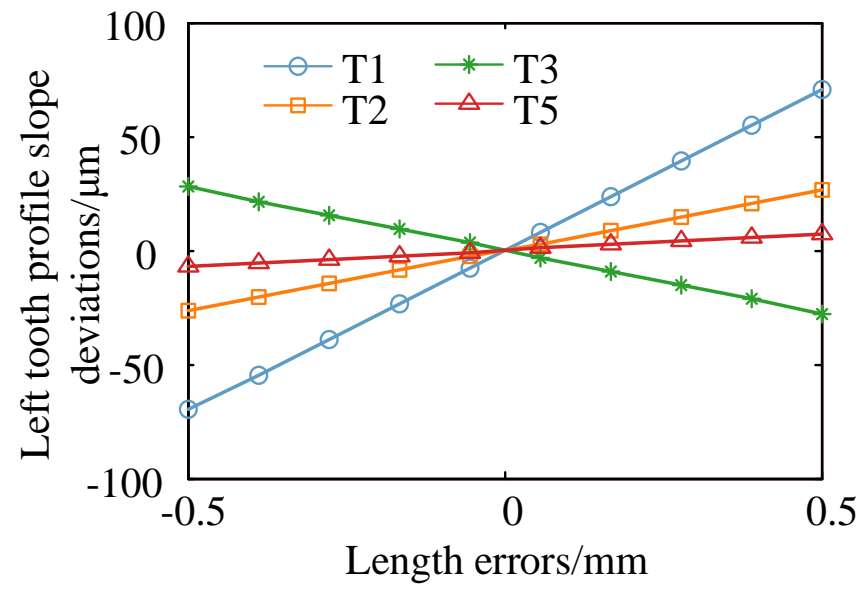

Figure 12. Relationship between tooth profile slope deviations and length errors.

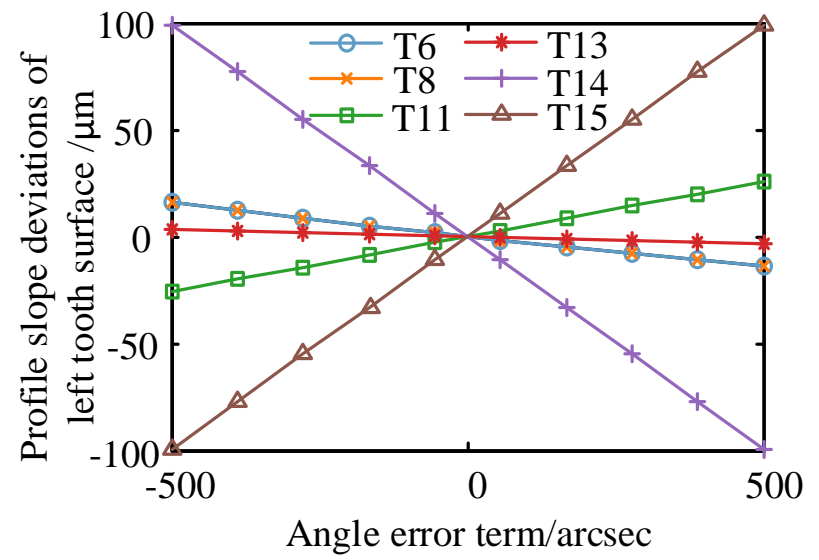

Figure 13. Relationship between tooth profile slope deviations and angle errors. 


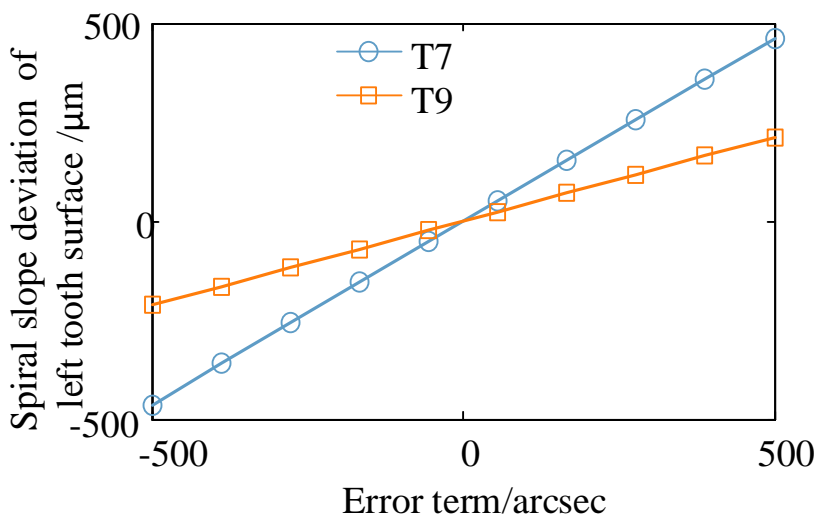

Figure 14. Relationship between spiral slope deviations, and T7 and T9.

\subsection{Optimized Distribution of Assembly Errors}

Based on the analysis mentioned above, one error term affects several tooth surface deviations, and one tooth surface deviation may be affected by several error terms. From an empirical point of view, to ensure ground tooth surface deviations, assembly error terms of profile grinding machines should be as small as possible. However, smaller assembly errors are bound to require higher accuracy of assembly parts. Excessively high accuracy is difficult to manufacture, and the machining cost will increase sharply. Furthermore, among these error terms, some have the same effect on certain tooth surface deviations, while others have opposite effects on the certain tooth surface deviation. Therefore, a certain tooth surface deviation may be eliminated by a reasonable combination of some bigger error terms, which indicates the necessity for optimized distribution of assembly errors. In the meantime, bigger allowable assembly errors are beneficial for assembly operations of profile grinding machines.

The maximization of assembly error terms is the first objective for the present optimization problem. Considering the convenience of assembly operations, each assembly error should be relatively harmonious. The minimization of the disparity of assembly error terms is determined as the second objective. Constraint conditions are the expected tooth surface deviations and the allowable range of each assembly error term. The two objective functions are expressed as Equations (7) and (8). The weighted coefficients of the two functions are $c_{1}=0.5, c_{2}=0.5$, respectively.

$$
\begin{gathered}
\mathrm{f}_{1}\left(\mathrm{~T}_{\mathrm{i}}\right)=\min \sum_{0}^{15} \frac{1}{\mathrm{~T}_{\mathrm{i}}}(\mathrm{i}=1,2,3, \ldots \ldots, 15) \\
\mathrm{f}_{2}\left(\mathrm{~T}_{\mathrm{i}}\right)=\min \left(\max \left\{\mathrm{T}_{\mathrm{i}}\right\}-\min \left\{\mathrm{T}_{\mathrm{i}}\right\}\right) \quad(\mathrm{i}=1,2,3, \ldots \ldots, 15)
\end{gathered}
$$

where $T_{i}$ represents the value of the ith error term.

According to the fourth grade accuracy of gears in ISO:1328-1:2013, the constraint conditions are expressed as Equation (9).

$$
\begin{gathered}
6.0 \leq \mathrm{f}_{\mathrm{s}} \leq 12.0 \\
6.5 \leq \mathrm{f}_{\mathrm{H} \alpha \mathrm{l}} \leq 13.0 \\
5.0 \leq \mathrm{f}_{\mathrm{H} \beta 1} \leq 12.0 \\
\mathrm{EI}_{\mathrm{T}_{\mathrm{i}}} \leq \mathrm{T}_{\mathrm{i}} \leq \mathrm{ES}_{\mathrm{T}_{\mathrm{i}}}(\mathrm{i}=1,2, \ldots \ldots 15)
\end{gathered}
$$

where the tooth surface deviations were calculated from the evaluation approach in Section 3 and the allowable range of each assembly error term can be obtained from Ref. [28].

The commonly used methods for optimization problems include mathematical methods (gradient descent and conjugate gradient) and heuristic methods (simulated anneal ing algorithm and genetic algorithm). The genetic algorithm (GA) is a heuristic optimization method mimicking the principles of natural genetics and natural selection in search and 
optimization procedures. The GA hopes to converge on a better solution by beginning with a set of potential solution, changing them through several generations. The solution of an optimization problem with the GA algorithm begins with a set of potential solution that is known as chromosomes. The entire set of these chromosomes comprises populations that are randomly selected. The entire set of these chromosomes evolve during several generations or iterations. The GA is suitable for optimization with complicated constraints and is widely used in many fields for optimizing machining parameters [29]. Using the GA, a strategy for selecting assembly errors is formulated, and the evaluation approach in Section 3 is embedded into the GA to calculate the tooth surface deviation. In order to cope with the multi-object optimization issue, the fitness function is established by the penalty function method, combining object function and constraint condition. Over successive generations, the population evolves toward an optimal solution. The flowchart for selecting assembly errors is shown in Figure 15.

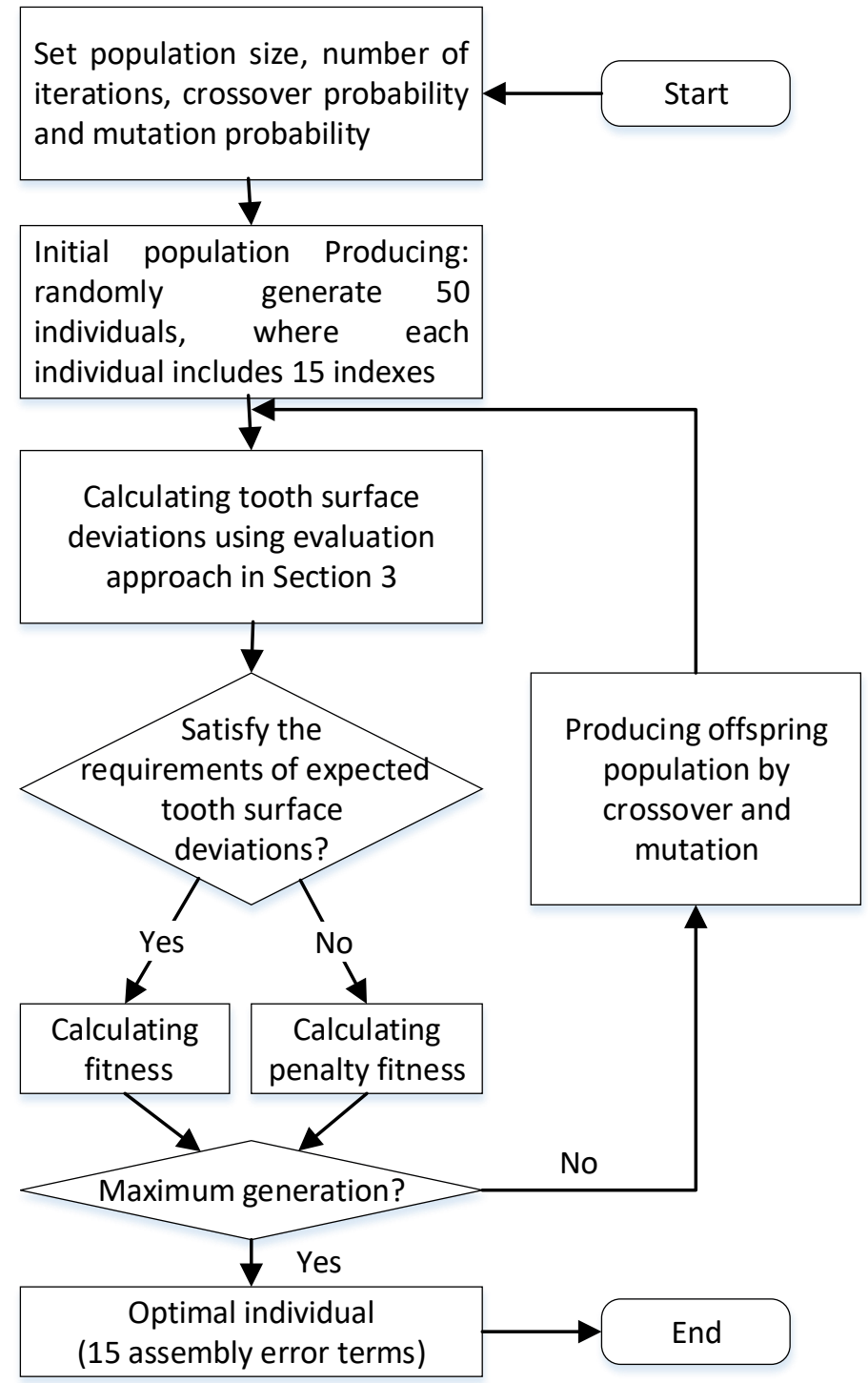

Figure 15. Flowchart for selecting assembly errors based on the GA.

In the current study, the GA was implemented using the MATLAB programming platform, in which the crossover probability was 0.98 , the mutation probability was 0.05 , the number of iterations was 500, and the population size was 50. The optimization results are shown in Table 4. 
Table 4. Assembly errors of the optimized distribution for the profile grinding system.

\begin{tabular}{|c|c|c|c|c|c|c|c|}
\hline Number & Symbol & Unit & Value & Number & Symbol & Unit & Value \\
\hline T1 & $\delta D_{\mathrm{x}}$ & $\mathrm{mm}$ & 0.03 & T9 & $\delta \beta_{0,1 \mathrm{~s}}$ & arcsec & 15 \\
\hline $\mathrm{T} 2$ & $\delta D_{\mathrm{y}}$ & $\mathrm{mm}$ & 0.05 & $\mathrm{~T} 10$ & $\delta \beta_{0,3 \mathrm{~s}}$ & arcsec & 50 \\
\hline T3 & $\delta y_{4 \mathrm{~d}, 5 \mathrm{~s}}$ & $\mathrm{~mm}$ & 0.05 & T11 & $\delta \beta_{4 \mathrm{~d}, 5 \mathrm{~s}}$ & arcsec & 10 \\
\hline $\mathrm{T} 4$ & $\delta D_{\mathrm{Z}}$ & $\mathrm{mm}$ & 0.2 & T12 & $\delta \varphi_{\mathrm{c}}$ & arcsec & 20 \\
\hline T5 & $\delta z_{5 \mathrm{~d}, 6 \mathrm{~s}}$ & $\mathrm{~mm}$ & 0.2 & T13 & $\delta \gamma_{4 \mathrm{~d}, 5 \mathrm{~s}}$ & arcsec & 20 \\
\hline T6 & $\delta \varphi_{\mathrm{a}}$ & arcsec & 50 & T14 & $\delta \gamma_{0,6 \mathrm{~s}}$ & arcsec & 20 \\
\hline T7 & $\delta \alpha_{0,1 \mathrm{~s}}$ & arcsec & 30 & & & & \\
\hline T8 & $\delta \alpha_{6 \mathrm{~d}, 7 \mathrm{~s}}$ & arcsec & 20 & T15 & $\partial \gamma_{6 \mathrm{~d}, 7 \mathrm{~s}}$ & arcsec & 20 \\
\hline
\end{tabular}

\subsection{Gear Profile Grinding Test}

To verify the effect of the proposed optimization method of assembly error terms, a large-scale CNC gear profile grinding machine was optimized by Nanjing Gongda CNC Technology Co., Ltd. based on the optimization results. As well known, a high level of investment is required to have a large machine tool in the lab, which is a limiting factor. Therefore, most of the advances in the field of large machine tools are supported by the industry. Two SKMC-1200W/08 CNC gear profile grinding machines were assembled. All of the materials and components used in the two machines were identical, while the assembly errors shown in Table 4 were adjusted to different values intentionally. The empirical values of assembly errors were conducted on the one machine, and the optimization values were conducted on the other machine. Among the empirical values of assembly errors, the length error was $0.02 \mathrm{~mm}$, and the angle error was $0.2^{\circ}$, which was approximately equal to 12.5 arcsec. In order to ensure the measurement accuracy, the API laser tracker, widely applied in the assembling of aircrafts, ships, etc., was used to measure the length error and angle error of large grinding machines. Its measuring accuracy for length error was $5 \mu \mathrm{m}$ and the measuring accuracy for angle error was $10^{\prime \prime}$.

The gear profile grinding tests were carried out with identical machining parameters. The related parameters of gear grinding were set as the values shown in Table 3. The grinding process is illustrated in Figure 16. In order to ensure the comparability of tests, the same semi-finishing gear was ground on the two machines successively. On each profile grinding machine, one tooth was ground completely. After finishing, the gear was measured on a Wenzel CMM, and the measurement reports are shown in Table 5. Both tooth profile deviations and spiral deviations reached fourth grade accuracy in ISO:1328-1:2013. The results show that the optimized distribution of assembly errors can meet the requirements of expected tooth surface deviations. In addition, assembly operations of large machines are more difficult with respect to conventional size machines and need to be addressed. The results also provide information about which assembly error terms can be relaxed for the profile grinding machine designer or manufacturer.

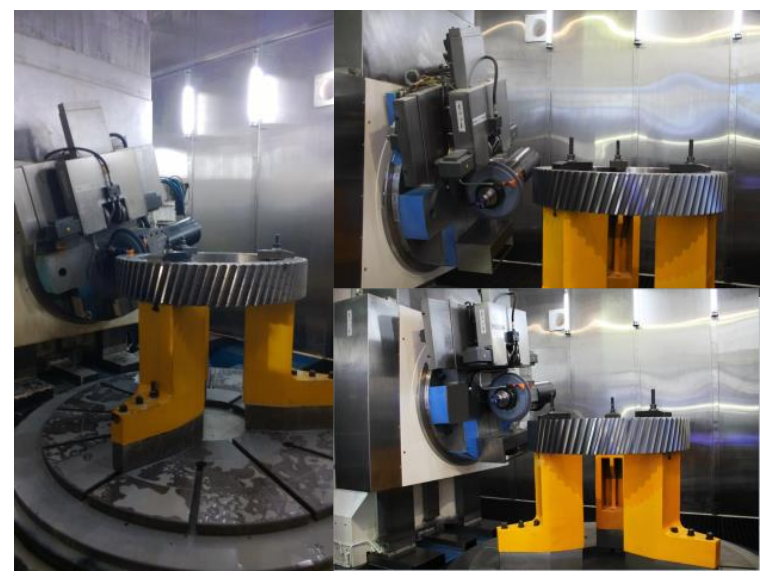

Figure 16. The grinding process of the SKMC-1200W/08 gear profile grinding machine. 
Table 5. Measurement results of the tooth profile deviations and spiral deviations.

\begin{tabular}{cccc}
\hline \multicolumn{2}{c}{ Left Tooth Surface } & \multicolumn{2}{c}{ Right Tooth Surface } \\
\hline$f_{\mathrm{H} \alpha} / \mu \mathrm{m}(\mathrm{Q})$ & $f_{\mathrm{H} \beta} / \mu \mathrm{m}(\mathrm{Q})$ & $f_{\mathrm{H} \alpha} / \mu \mathrm{m}(\mathrm{Q})$ & $f_{\mathrm{H} \beta} / \mu \mathrm{m}(\mathrm{Q})$ \\
\hline $7.7(4)$ & $7.9(4)$ & $8.2(4)$ & $7.3(4)$ \\
\hline
\end{tabular}

Note: the numbers in brackets are precision levels.

\section{Conclusions}

This paper proposed a method to evaluate the effect of assembly errors on ground tooth deviations for large-scale CNC gear profile grinding machines. Specifically, a tooth surface model including assembly errors and an evaluation approach for tooth surface deviations are developed. This new approach has the following conclusions: (1) Among the 15 assembly errors, the tooth profile slop deviation is affected by T1, T2, T3, T5, T6, T8, T11, T13, T14, and T15. The influences of T1, T3, T6, and T8 on the left and right tooth surfaces are symmetrical, while other influences on the left and right tooth surfaces are reversely symmetric. The spiral deviations are mainly affected by T7 and T9. T7 has an inverse symmetric effect on the left and right tooth surfaces, and T9 has an antisymmetric effect on the left and right tooth surfaces. The tooth thickness deviation is greatly affected by T1. The deviations in ground tooth surfaces affected by T4, T10, and T12 are few. (2) Cases studies with error distributions and cutting experiments on large-scale CNC gear profile grinding machines verify the practicability and effectiveness of this distribution method. The results provide information about which assembly error terms can be relaxed for the profile grinding machine designer or manufacturer.

Author Contributions: Conceptualization, W.D.; methodology, H.Z.; software, W.H.; validation, H.Z. and W.H.; formal analysis, Y.L.; investigation, Y.L.; resources, H.Z.; data curation, W.H.; writingoriginal draft preparation, W.H.; writing - review and editing, W.D.; visualization, W.H.; supervision, W.D.; project administration, W.D.; funding acquisition, W.D. All authors have read and agreed to the published version of the manuscript.

Funding: This research was funded by the National Natural Science Foundation of China, Grant no. 51405220; Young academic leaders program of Jiangsu Qinglan Project.

Data Availability Statement: The data underlying this article will be shared upon reasonable request to the corresponding author.

Acknowledgments: The authors appreciate the contributions of Nanjing Gongda CNC Technology Co., Ltd. to this paper for its assistance in the experiments.

Conflicts of Interest: The authors declare no conflict of interest. Nanjing Gongda CNC Technology Co., Ltd. provides large-scale CNC gear profile grinding machines for experiments.

\section{References}

1. Wegener, K.; Bleicher, F.; Krajnik, P.; Hoffmeister, H.-W.; Brecher, C. Recent developments in grinding machines. CIRP Ann.-Manuf. Technol. 2017, 66, 779-802. [CrossRef]

2. Wang, K.; Sheng, X.; Kang, R. Volumetric error modelling, measurement, and compensation for an integrated measurementprocessing machine tool. Proc. IMechE Part C J. Mech. Eng. Sci. 2010, 224, 2477-2486. [CrossRef]

3. Heinzel, C.; Wagner, A. Fine finishing of gears with high shape accuracy. CIRP Ann.-Manuf. Technol. 2013, 62, 359-362. [CrossRef]

4. $\quad$ Rowe, W.B. Principles of Modern Grinding Technology, 3rd ed.; Elsevier: Oxford, UK, 2013.

5. Araujo, J.B.; Oliveira, J.F. Evaluation of two competing machining processes based on sustainability indicators, in leveraging technology for a sustainable world. In Proceedings of the 19th CIRP Conference on Life Cycle Engineering, Berkeley, CA, USA, 23-25 May 2012.

6. Litvin, F.L.; Fuentes, A. Gear Geometry and Applied Theory, 2nd ed.; Cambridge University Press: Cambridge, UK, 2004.

7. Denkena, B.; Preising, D.; Woiwode, S. Gear profile grinding with metal bonded CBN tools. Prod. Eng.-Res. Dev. 2015, 9, 73-77. [CrossRef]

8. Fong, Z.; Chen, G. Gear flank modification using a variable lead grinding worm method on a computer numerical control gear grinding machine. J. Mech. Des. 2016, 138, 083302-1-083302-10. [CrossRef]

9. Wu, Y.; Fan, C. Mathematical modeling for screw rotor form grinding on vertical multi-axis computerized numerical control form grinder. J. Manuf. Sci. Eng. 2013, 135, 051020-1-051020-13. [CrossRef] 
10. Chen, G.; Mei, X.; Li, H. Geometric error modeling and compensation for large-scale grinding machine tools with multi-axes. Int. J. Adv. Manuf. Technol. 2013, 69, 2583-2592. [CrossRef]

11. Zhou, B.; Wang, S.; Fang, C.; Sun, S.; Dai, H. Geometric error modeling and compensation for five-axis CNC gear profile grinding machine tools. Int. J. Adv. Manuf. Technol. 2017, 92, 2639-2652. [CrossRef]

12. Wang, S.; Zhou, B.; Fang, C.; Sun, S. Research on thermal deformation of large CNC gear profile grinding machine tools. Int. J. Adv. Manuf. Technol. 2017, 91, 577-587. [CrossRef]

13. Yang, H.; Huang, X.; Guo, E. Analysis and compensation for pitch error in forming manufacturing big gears. Modul. Mach. Tool Autom. Manuf. Tech. 2018, 10, 59-63.

14. Zhang, H.; Fang, C.; Guo, E.; Huang, X. Accurate lead modification of CNC gear profile grinding based on five-axis motions optimization. Comput. Integr. Manuf. Syst. 2014, 20, 3058-3065.

15. Guo, E.; Huang, X.-D.; Fang, C.-G.; Yuan, H. Contact lines optimization method for improving tooth-trace modification accuracy of form grinding. Comput. Integr. Manuf. Syst. 2014, 20, 134-141.

16. Ding, G.; Zhang, S.; Zhao, D.; Zhao, D. Interference study of gear form grinding based on induced normal curvature. Chin. J. Mech. Eng. 2016, 52, 197-204. [CrossRef]

17. Li, T.; Yan, P.; Yu, G.; Ji, W. Solving the problem of interference of forming grinding wheel based on MATLAB. Tool Eng. 2021, 55, 101-104.

18. Ding, S.; Huang, X.; Yu, C.; Wang, W. Actual inverse kinematics for location error compensation of five-axis machine tool. Comput. Integr. Manuf. Syst. 2021, 27, 1300-1308.

19. Zhao, F.; Mei, X.; Jiang, G.; Tao, T.; Shi, J. Molding and characters analysis error of numerical control machine tool. J. Shanghai Jiaotong Univ. 2013, 47, 703-708.

20. Lee, R.S.; Lin, Y.H. Applying bidirectional kinematics to assembly error analysis for five-axis machine tools with general orthogonal configuration. Int. J. Adv. Manuf. Technol. 2012, 62, 1261-1272. [CrossRef]

21. Xia, C.; Wang, S.; Sun, S.; Lin, X.; Huang, X. Geometric error to tooth surface error model and identification of crucial errors in five-axis CNC gear profile grinding machines. Comput. Integr. Manuf. Syst. 2020, 26, 1191-1201.

22. Zhao, W.; Zhang, X.; Lv, D.; Zhang, J. Technical status and strategies for domestic CNC machine tools. Aeronaut. Manuf. Technol. 2016, 9, 16-22.

23. Sun, Y.; Liu, Y.; Ran, Y.; Zhou, Q. Assembly precision prediction method of numerical control machine tools based on meta-action Mech. Sci. Technol. Aerosp. Eng. 2017, 36, 1734-1739.

24. Guo, J.; Li, B.; Hong, J.; Li, X. Assembly adjustment process planning of precision machine tools based on optimal estimation of variation propagation. Chin. J. Mech. Eng. 2020, 56, 172-180.

25. Wang, Z.; Jiang, X.; Liu, W.; Shi, M.; Yang, S.; Yang, G. Precision prediction and error propagation model of remanufacturing machine tool assembly process. Comput. Integr. Manuf. Syst. 2021, 27, 1300-1308.

26. Chen, X.; Morgan, M.N. Advances in quality and productivity in precision grinding-A review of selected research. In Proceedings of the ASME 2016 International Manufacturing Science and Engineering Conference, Blacksburg, VA, USA, 27 June-1 July 2016

27. Uriarte, L.; Zatarain, M.; Axinte, D.; Yagüe-Fabra, J.; Ihlenfeldt, S.; Eguia, J.; Olarra, A. Machine tools for large parts. CIRP Ann.-Manuf. Technol. 2013, 62, 731-750. [CrossRef]

28. Hu, W.; Wang, X. Grinding Machines Part3: Profile Grinding Machines Accuracy Inspection; China Machine Press: Beijing, China, 2014.

29. Bhoskar, T.; Kulkarni, O.K.; Kulkarni, N.K.; Patekar, S.L.; Kakandikar, G.M.; Nandedkar, V.M. Genetic algorithm and its applications to mechanical engineering: A review. Mater. Today 2015, 2, 2624-2630. [CrossRef] 